\title{
Thermally stimulated discharge current (TSDC) and dielectric constant of semiconducting glasses
}

\author{
D K BURGHATE ${ }^{\dagger}$, V S DEOGAONKAR ${ }^{\dagger}$, S B SAWARKAR*, S P YAWALE \\ and $S$ V PAKADE \\ Department of Physics, Polytechnic Badnera, Amravati 444 701, India \\ ${ }^{\dagger}$ Department of Physics, Shri Shivaji Science College, Amravati 444 603, India \\ Department of Physics, Government Vidarbha Institute of Science and Humanities, Amravati 444 604, India
}

MS received 9 October 2001; revised 18 April 2002

\begin{abstract}
In this paper the results of thermally stimulated discharge current (TSDC) and dielectric constant for $40 \mathrm{PbO}-60 \mathrm{Bi}_{2} \mathrm{O}_{3}$ glass thermoelectrets are presented. Measurements of TSDC and dielectric constant, $\varepsilon^{\prime}$, have been carried out in the temperature range $30-300^{\circ} \mathrm{C}$. The thermoelectrets were prepared at different polarizing fields. The various observed peaks in the thermograms are discussed on the basis of space charge polarization. The trap energy is evaluated from the Garlick-Gibson plot of initial rise method. Similarly other parameters such as relaxation time, charge release etc are evaluated.
\end{abstract}

Keywords. Semiconducting glass; TSDC; trap energy; dielectric constant.

\section{Introduction}

A good amount of work has been reported on thermally stimulated discharge technique in polymeric materials during the past few years. Sessler (1980) gave a broad definition of the electret. He defined electret as a dielectric material exhibiting a quasi-permanent electric charge. Eguchi (1919) discovered the first electret, now known as thermoelectret. Khare et al (1998) measured the thermally stimulated discharge current (TSDC) and electrical conductivity in metal (1) and ethyl cellulose-metal (1)/(2) systems. TSDC of polymer has become a widely used experimental technique for the investigation of various material parameters such as charge storage properties, determination of mean depth of the internal charge, activation energies of traps and trap structure of the material. It is only in recent years that the possibility of technological application of electrification of polymer due to its contact with metal has been discovered (Srivastava et al 1981). The availability of new measuring techniques such as thermally stimulated discharge current (Turnhout 1975) has freshened interest in achieving a better understanding and application of the phenomena. Fridkin and Zheludev (1961), Gross (1964) and Latour (1972) extensively reviewed the methods of formation of thermoelectrets. Basically, three kinds of phenomena can occur in thermal charging, viz. (i) internal polarization with the sign of heterocharge due to dipole alignment or charge separation within the dielectric i.e. dielectric absorption,

\footnotetext{
*Author for correspondence
}

(ii) homocharge deposition due to spark discharges in the air gaps and (iii) homocharge injection through contacting electrodes.

Pissis et al (1994) reported the electric and dielectric measurements of several conducting (polyethylene oxide) PEO-based electrolytes, by using thermally stimulated depolarization current (TSDC) and thermally stimulated polarization currents (TSPC). Negau and Negau (1994) obtained new results in thermally stimulated discharge current (TSDC) peak above room temperature.

Hong and Day (1979) applied the techniques of thermally stimulated polarization and depolarization current for studying alkaline ion motion in glasses of sodium silicate and lead silicate. The peaks observed are discussed on the basis of d.c. conductivity and short range $\mathrm{Na}^{+}$ion motion. The thermal detrapping of $\mathrm{Na}^{+}$ions from the $\mathrm{Si}-\mathrm{SiO}_{2}$ or $\mathrm{SiO}_{2}-\mathrm{Al}$ electrode interface produces the thermally stimulated ionic current peaks from which the trap depths and $\mathrm{Na}^{+}$ions mobility can be calculated (Hickmott 1973, 1975). Most of the peaks which occurred in the thermograms of alkali silicate glasses are very much related to the structure and mobility of ions. The localized ion motion around the non-bridging oxygen ion and the limited conduction pathways are responsible for the TSDC peaks in high and low temperature regions (Agarwal and Day Delbert 1982). Sawarkar et al (1997) studied the depolarization currents in semiconducting $50 \mathrm{PbO}-50 \mathrm{~B}_{2} \mathrm{O}_{3}$ glasses and evaluated the various parameters such as trap depth, trap density, activation energy etc. The results have been explained on the basis of space charge polarization and distribution of trap levels of charges inside the thermoelectret. 
Many workers (Pillai et al 1973; Pillai and Mollah 1980) have studied depolarization current in polymer thermoelectrets. Pasek and Magierski (1986) measured thermally stimulated discharge current in UV-irradiated borosilicate glasses containing alkali ions. Hong and Day (1979) and Doi (1983) used this technique of measurement of thermally stimulated current to investigate alkaline ion motion in glasses.

The detailed survey of literature revealed that the thermally stimulated discharge technique is extensively applied for the study of polymer thermoelectrets only. However, work on TSDC measurement is very scant in glass thermoelectret. Therefore, it has been decided to study the depolarization in lead-bismuth glass, using thermally stimulated discharge current (TSD) technique. The basic principle of this technique is to study the charge decay by heating the electret at a constant rate. This technique is a basic tool to identify and evaluate the dipole reorientation process, trapping and recombination levels in electrets.

\section{Experimental}

\subsection{Glass sample preparation}

The glass samples were prepared from AnalaR grade chemicals, $\mathrm{PbO}$ and $\mathrm{Bi}_{2} \mathrm{O}_{3}$. The component composition was $40 \mathrm{~mol} \%$ and $60 \mathrm{~mol} . \%$, respectively. Appropriate amounts in mol. $\%$ of $\mathrm{PbO}$ and $\mathrm{Bi}_{2} \mathrm{O}_{3}$ in powder form were weighed on K-Roy monopan balance having an accuracy of $\pm 0.00001 \mathrm{~g}$. Repeated grinding of mixture was done to ensure homogenization. Homogeneous mixture was then transferred to fire clay crucibles which was then subjected to melting in an automatically controlled muffle furnace at temperatures ranging from 1000 to $1200 \pm$ $10^{\circ} \mathrm{C}$. The duration of melting was generally $4 \mathrm{~h}$. The homogenized molten mass was cast in steel discs of $2.5 \mathrm{~cm}$ length and $0.7 \mathrm{~cm}$ thickness. The samples were quenched at $200^{\circ} \mathrm{C}$ to avoid cracking and shattering of glass.
After quenching, all samples were immediately transferred to an annealing furnace. Samples were annealed at $350^{\circ} \mathrm{C}$ for $2 \mathrm{~h}$. The effect of annealing is to remove the air bubbles or cavities, if any, which may be formed by sudden quenching. All glasses after annealing were subjected to finishing processes such as cleaning and polishing. Sufficient number of glass samples were prepared from the same batch of composition.

For attaining exact parallel and plane surfaces of glasses, a fine lapping paper was used. A conducting silver paint was applied to either side of glass samples. All the samples were baked at $150^{\circ} \mathrm{C}$ for $2 \mathrm{~h}$, for removal of mechanical stresses, if any, developed during polishing. Thickness of each sample was $0.380 \mathrm{~cm}$. The X-ray diffractograms of all the samples were obtained for checking the amorphous nature of the sample. The absence of peak in the X-ray spectra, confirmed the amorphous nature of glass samples (figure 1).

\subsection{Electret preparation}

The glass sample $40 \mathrm{PbO}-60 \mathrm{Bi}_{2} \mathrm{O}_{3}$ was mounted into the sample holder. The polarizing field, $E_{\mathrm{p}}$, was maintained for $30 \mathrm{~min}$ between two opposite faces of glass at room temperature $\left(30^{\circ} \mathrm{C}\right)$. Then the electric field across the sample was removed and the sample was short-circuited for $15 \mathrm{~min}$ to remove the stray charges by wrapping the sample in a conducting aluminum foil. The electrets were prepared at different polarizing fields: $E_{\mathrm{p}}=78 \mathrm{kV} / \mathrm{m}$, $156 \mathrm{kV} / \mathrm{m}, 234 \mathrm{kV} / \mathrm{m}, 312 \mathrm{kV} / \mathrm{m}$ and $390 \mathrm{kV} / \mathrm{m}$, respectively at room temperature.

\subsection{Measurement of thermally stimulated discharge current}

After electret formation the sample holder assembly was placed in high temperature furnace. The sample was short circuited through a sensitive picoammeter (Model DPA III Scientific Equipment, Roorkee, having accuracy \pm $1 \mathrm{pA})$ for the measurement of discharge current. Then the sample was heated at a uniform rate of $3 \cdot 5^{\circ} \mathrm{C} / \mathrm{min}$ from

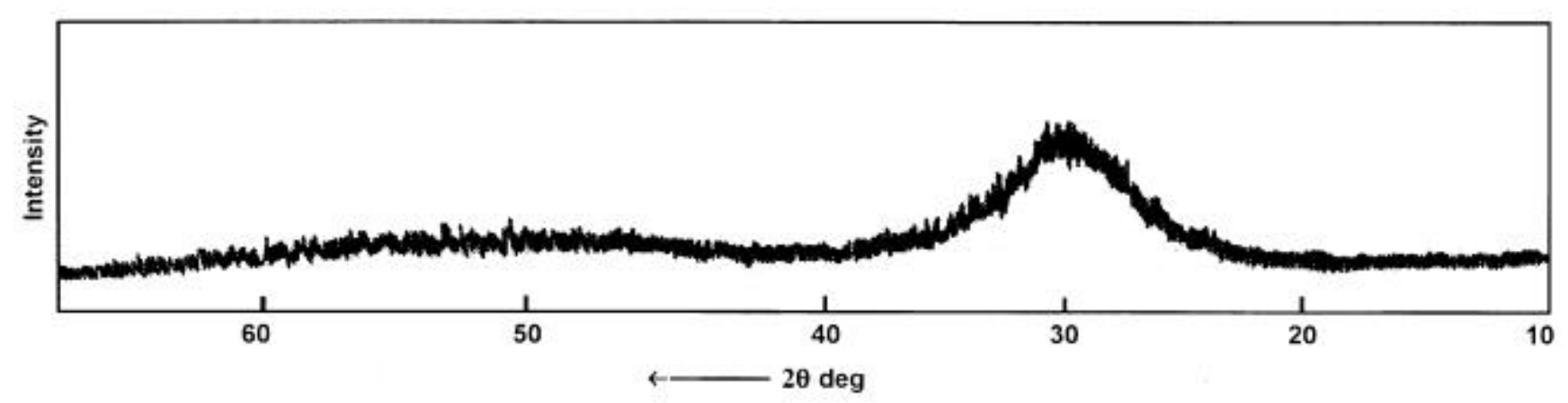

Figure 1. X-ray diffractogram of glass sample. 
30 to $300^{\circ} \mathrm{C}$. The short circuit current was also measured for unpolarized sample. The temperature was recorded by digital thermometer having an accuracy of $\pm 1{ }^{\circ} \mathrm{C}$.

The purpose of preparation of electrets was to observe the effect of polarizing field, $E_{\mathrm{p}}$, on the properties of electrets.

\section{Results}

The results of the present study are reported in the thermograms which are curves between TSDC current and temperature of the sample at different polarizing fields (figure 2). The experimental findings are summarized as below.

(I) Each curve (excepting curve (a) for unpolarized sample) shows one $\alpha$-peak at a temperature of about 50 to $60^{\circ} \mathrm{C}$ in the +ve current i.e. heterocharge region.

(II) (a) Each curve (excepting curve (a)) shows a reversal of polarity, which occurs gradually, (b) the unpolarized sample curve (a) shows -ve current only i.e. in the homocharge region and (c) the current in the homocharge region increases steeply beyond about $200^{\circ} \mathrm{C}$ in almost all curves.

(III) The curve (c) for sample polarized at $156 \mathrm{kV} / \mathrm{m}$ presents a second current peak, $\alpha_{2}$, in the homocharge region

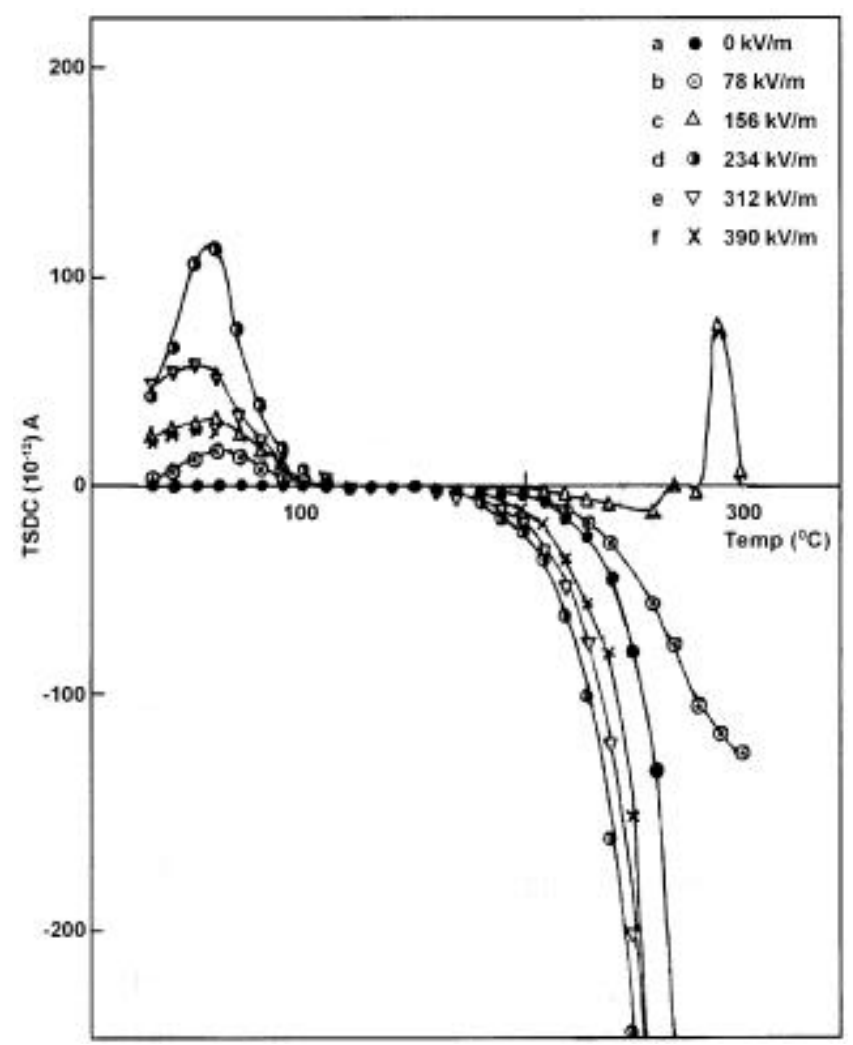

Figure 2. Thermally stimulated discharge current vs temperature plot of glass sample. and a third current peak, $\alpha_{3}$, which appreciably is larger than its $\alpha_{1}$ peak.

(IV) The peak current, $I_{\max }$, and hence the amount of stored charge first increases with polarizing field, attains a maximum value for curve (d) at field $234 \mathrm{kV} / \mathrm{m}$ and then decreases again (figure 2).

\section{Discussion}

The intensity of polarizing electric field, $E_{\mathrm{p}}$, appreciably affects properties of the electret (Tareev 1979). When polarizing electric field, $E_{\mathrm{p}}$, is small (approximately up to $1 \mathrm{mV} / \mathrm{m}$ ), the obtained electret possesses charges opposite to the polarity of polarizing voltage, i.e. heterocharge. If the $E_{\mathrm{p}}>1 \mathrm{mV} / \mathrm{m}$, the electret receives charges of the same sign as the electrodes with which the surfaces of the electret were in contact during polarization i.e. homocharge.

The observed increase in $I_{\max }$ (and the total charge stored) with increase of polarizing field (up to $234 \mathrm{kV} / \mathrm{m}$ ) may be due to the increased dipolar polarization. The dipoles get a better chance to orient themselves in the field direction, due to increased field. Considering only internal polarization, the two mechanisms, which are likely to be operative in the polarization process, are the relaxation of the polar group and space charge polarization. The disorientation of the dipoles merely requires local rotation and hence the current peak $(\alpha)$ appears at lower temperature (than the space charge polarization peak which may appear at higher temperature).

At higher temperature the self-motion of the space charges is accompanied by a second neutralization mechanism viz. recombination with thermally generated carriers. These carriers are generated uniformly in the entire specimen by dissociation of neutral entities. These charges become more mobile at higher temperature and constitute a homocurrent in the internal field of the electret. This current is opposite to the current due to dipolar disorientation. As the temperature is raised above heteropeak, the homocurrent starts increasing, as the number of thermally generated carriers increases. So a reversal is observed from heterocurrent to homocurrent. As temperature increases the current goes on increasing in the homoside for all curves except curve (c). Verma et al (1990) made similar observation on bakelite electrets.

In case of curve (c) $\left[E_{\mathrm{p}}=156 \mathrm{kV} / \mathrm{m}\right]$, the increase of homocurrent is quite small, and yet it shows a homocurrent current peak, $\alpha_{2}$. This is because of the dipoles of the closed dielectric domains, which are broken at this temperature and start contributing to the main displacement current, $I_{\text {het }}$, whose direction is opposite to the direction of $I_{\text {hom. }}$. This results in the homo peak $\alpha_{2}$ at about $250^{\circ} \mathrm{C}$. The origin of the hetero-charge peak, $\alpha_{1}$ (and homocharge peak, $\alpha_{2}$ ) can be explained by two-charge theory of Gross $(1944,1949)$ as $I=I_{\text {het }}+I_{\text {hom }}$. The resultant 
Table 1. TSDC parameters of glass samples polarized at fixed polarizing temperature and various polarizing fields.

\begin{tabular}{lccccccr}
\hline & $\begin{array}{c}\text { Polarizing } \\
\text { field, } \\
E_{\mathrm{p}}(\mathrm{kV} / \mathrm{m})\end{array}$ & $\begin{array}{c}\text { Peak } \\
\text { temperature, } \\
T_{\mathrm{m}}\left({ }^{\circ} \mathrm{C}\right)\end{array}$ & $\begin{array}{c}\text { Trap energy, } \\
E(\mathrm{eV})\end{array}$ & $\begin{array}{c}\text { Characteristic } \\
\text { relaxation time, } \\
\tau_{0}(\mathrm{sec})\end{array}$ & $\begin{array}{c}\text { Attempt to escape } \\
\text { frequency, } \\
\mathrm{v}_{0}\left(\mathrm{sec}^{-1}\right)\end{array}$ & $\begin{array}{c}\text { Capture cross } \\
\text { section, } \\
\sigma_{\mathrm{D}}\left(\mathrm{m}^{2}\right)\end{array}$ & $\begin{array}{c}\text { Charge released } \\
\left(\mathrm{Q} 10^{-8} \mathrm{coulomb}\right)\end{array}$ \\
\hline 1 & 78 & 60 & $0 \cdot 456$ & $4.60 \times 10^{-5}$ & $4 \cdot 06 \times 10^{4}$ & $1 \cdot 74 \times 10^{-25}$ & $3 \cdot 60$ \\
2 & 156 & 60 & $0 \cdot 099$ & $5 \cdot 27 \times 10^{1}$ & $7 \cdot 24 \times 10^{-2}$ & $3 \cdot 10 \times 10^{-31}$ & $9 \cdot 00$ \\
3 & 234 & 60 & $0 \cdot 368$ & $1 \cdot 21 \times 10^{-3}$ & $1 \cdot 13 \times 10^{3}$ & $4 \cdot 87 \times 10^{-27}$ & $24 \cdot 00$ \\
4 & 312 & 50 & $0 \cdot 108$ & $2 \cdot 96 \times 10^{1}$ & $1.97 \times 10^{-1}$ & $9 \cdot 00 \times 10^{-31}$ & $15 \cdot 00$ \\
5 & 390 & 50 & $0 \cdot 144$ & $6 \cdot 19$ & $5 \cdot 59 \times 10^{-1}$ & $2 \cdot 55 \times 10^{-30}$ & $9 \cdot 30$ \\
\hline
\end{tabular}

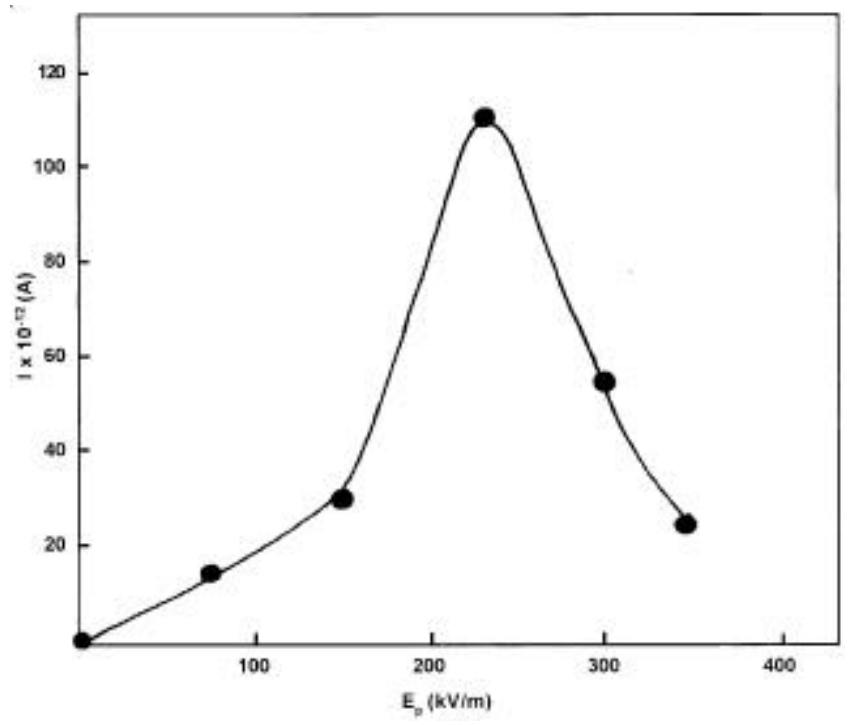

Figure 3. Variation of peak current with polarizing field.

current generated is proportional to the net current, $I_{\text {het }}{ }^{-}$ $I_{\text {hom }}$, since $I_{\text {het }}$ and $I_{\text {hom }}$ are assumed to have opposite sign. When the reorientation rate of dipoles is greater than the rate of neutralization by recombination with thermally generated carriers, we first find a heteropolar peak, $\alpha_{1}$.

Figure 3 shows the variation of heterocurrent for peak $(\alpha)$ with the polarizing field. It can be observed that the peak current increases with polarizing field up to 234 $\mathrm{kV} / \mathrm{m}$, becomes maximum and then falls again with further increase in polarizing field. This may be explained as below.

The reorientation of the dipoles due to the polarizing field increases until it reaches a maximum value corresponding to the maximum number of available dipoles, and this shows heteropolar peak, $\alpha_{1}$. Now even if the polarizing field is increased beyond this, there are no more dipoles to be reoriented and hence $I_{\text {het }}$ does not increase. On the contrary the rate of neutralization by recombination at higher fields should have increased. Thus the peak current decreases beyond polarizing field, $234 \mathrm{kV} / \mathrm{m}$. The values of TSDC parameters such as trap depth, characteristic relaxation time, attempt to escape frequency and capture cross section calculated by using

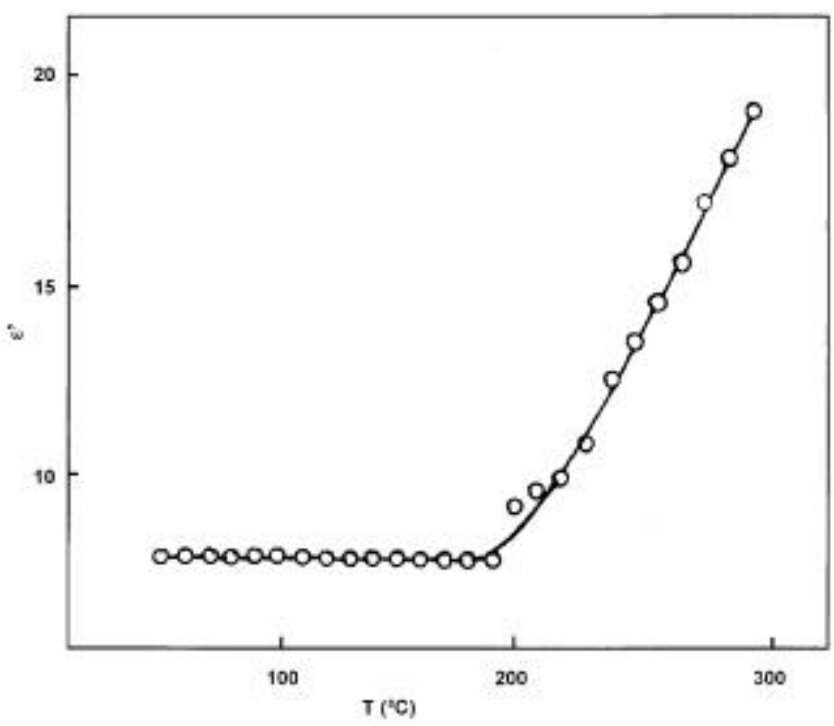

Figure 4. Variation of dielectric constant with temperature.

Garlick-Gibson (1948) method are reported in table 1. The relevant formulae for evaluation of these parameters are reported elsewhere (Sawarkar et al 1997). The charge released during the relaxation process calculated by measuring the area under TSDC peak (Simmons and Taylor 1972) is also reported in table 1. It is found that the charge released during relaxation process increases with increasing polarizing field up to $234 \mathrm{kV} / \mathrm{m}$ and then decreases with increasing field.

Figure 4 shows the variation of dielectric constant with temperature $\left(30-300^{\circ} \mathrm{C}\right)$ at frequency $1 \mathrm{kHz}$. It is observed that the dielectric constant is independent of temperature up to $190^{\circ} \mathrm{C}$ and beyond $190^{\circ} \mathrm{C}$ it increases rapidly. This increase in dielectric constant is due to a change in electronic structure and partly due to thermal expansion. The dielectric constant, $\varepsilon^{\prime}$, is found to be of the order of values of $\varepsilon^{\prime}$ for glasses appearing in the literature (Van-Hipple 1954). The change in dielectric constant at high temperature is a characteristic of Debye-type relaxation process where symmetrical distribution of relaxation time takes place.

If we compare the graph of $\varepsilon^{\prime}$ vs $T$ (figure 4), with the graph of zero polarizing field (figure 2), a similarity in 
nature is observed. The $\varepsilon^{\prime}$ of figure 4 and TSDC current of figure 2, remain almost constant up to about $200^{\circ} \mathrm{C}$. Beyond this the $\varepsilon^{\prime}$ as well as TSDC current starts suddenly increasing. This is in fact what is expected. The increased $\varepsilon^{\prime}$ and hence increased capacity to store and release more charge (homo) with rising temperature is anticipated for the unpolarized sample. Two independent approaches viz. by dielectric and TSDC measurements, lead to the same basic behaviour of the sample, thereby corroborating the experimental findings.

We are attempting to see whether any relation can be observed in the behaviour of the polarized sample and its dielectric constant. Further work in this direction is in progress.

\section{Acknowledgement}

The author is thankful to Prof. V G Bhamburkar, Principal, Shri Shivaji Science College, Amravati, for providing necessary laboratory facilities during the course of this work.

\section{References}

Agarwal A K and Day Delbert E 1982 J. Am. Ceram. Soc. 65 111

Doi A 1983 Jap. J. Appl. Phys. 22228

Eguchi M 1919 Proc. Phys. Math. Soc. Jpn 1326

Fridkin V M and Zheludev I S 1961 Photoelectrets and electrographic process (NY: Consultants Bureau)

Garlick G F J and Gibson A F 1948 Proc. Phys. Soc. (London) 60574
Gross B 1944 Rev. USA 6626

Gross B 1949 J. Chem. Phys. USA 17866

Gross B 1964 Charge storage in solid dielectrics (Amsterdam: Elsevier)

Hickmott T W 1973 Appl. Phys. Lett. 22267

Hickmott T W 1975 J. Appl. Phys. 462583

Hong C M and Day D E 1979 J. Mater. Sci. 142493

Hong C M and Day D E 1981 J. Am. Ceram. Soc. 6461

Khare P K, Verma A and Paliwal S K 1998 Bull. Mater. Sci. 21 207

Latour M 1972 Appl. Phys. (Paris) 7115

Negau E and Negau R 1994 Proc. ISE 8528

Pasek Ewa Rysiakiewiez and Magierski Wojciech 1986 Opt. Appl. XVI 273

Pillai P K C and Mollah M 1980 J. Macromol. Sci. Phys. B17 69

Pillai P K C, Jain K and Jain V K 1973 Indian J. Pure Appl. Phys. 11597

Pissis P, Laudat J, Thonas C, Apekis L and Kyritsis A 1994 Proc. ISE 8392

Sawarkar S B, Deogaonkar V S, Pakade S V and Yawale S P 1997 Indian J. Pure Appl. Phys. 35281

Sessler G M 1980 Electrets (Berlin: Springer-Verlag; New York: Heidelberg) pp 81-217

Simmons J G and Taylor G W 1972 Phys. Rev. 64804

Srivastava S K, Ranade J D and Srivastava A P 1981 Polymer 221645

Tareev B 1979 Physics of dielectric materials (Moscow: Mir publishers) p. 216

Turnhout J Van 1975 Thermally stimulated discharge of polymer electret (Amsterdam: Elsevier) p. 25

Verma J P, Thakur R S and Sinha S D 1990 Indian J. Pure Appl. Phys. 16281

Van-Hipple A R 1954 Dielectric materials and applications (London: Chapman and Hall) p. 309 